\title{
Programa de concientización jurídica en el empoderamiento de los derechos humanos, Pachacámac, 2016
}

\section{Program of Legal Awareness in the Empowerment of Human Rights, Pachacamac, 2016}

Jesús Manuel Galarza Orrilla;* Hada Consuelo Sifuentes Minaya;**

Godofredo Jorge Calla Colana***

http://dx.doi.org/10.21503/lex.v16i22.1647

* Derecho y Ciencias Políticas. Universidad Nacional Federico Villareal. Título: abogado por la Universidad Nacional Federico Villareal, 1982. Maestro en Derecho Civil, Universidad Inca Garcilaso de la Vega, 2003. Doctor en Derecho, Universidad Alas Peruanas, 2013. Decano de la Facultad de Derecho y Ciencia Política de la UAP.

Correo electrónico: j_galarza_o@uap.edu.pe

** Abogada. Bachiller en Derecho, USMP, 1998.Título de abogado, USMP, 2002. Maestro en Derecho Empresarial, UAP, 2007.

Correo electrónico: h_sifuentes@doc.uap.edu.pe

*** Posdoctoral en Ciencias de la Educación. Doctor en Educación, magíster en Gestión Educativa, maestro con mención en Evaluación y Acreditación de la Calidad de la Educación.

Correo electrónico: g_calla_c@doc.uap.edu.pe

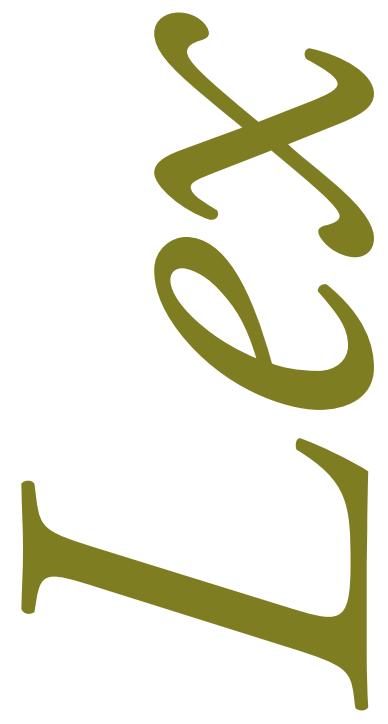




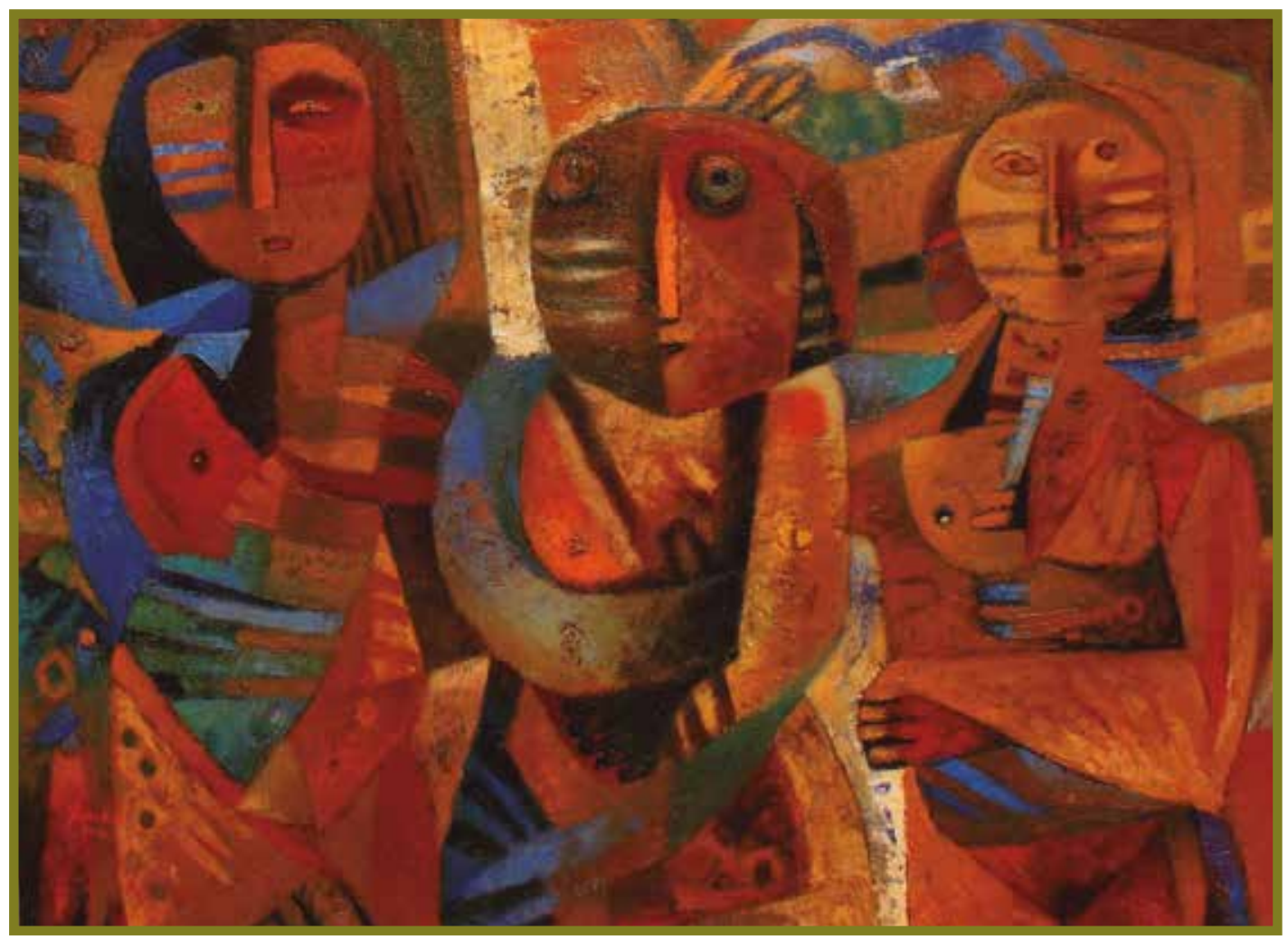

Niños jugando. Pintura. Juan Carlos Náñake. 


\section{RESUMEN}

El propósito de esta investigación es establecer la influencia en la aplicación del Programa de concientización jurídica en el empoderamiento de los derechos humanos en Pachacámac, 2016. Siendo el problema general: ¿̨cuál es la influencia de la aplicación del Programa de concientización jurídica en el empoderamiento de los derechos humanos en Pachacámac, 2016? Su hipótesis general fue: Sí, existe influencia en la aplicación del Programa de concientización jurídica en el empoderamiento de los derechos humanos en Pachacámac, 2016. Su enfoque fue cuantitativo. El tipo de investigación fue aplicada, el método de estudio fue deductivo-hipotético, su diseño fue cuasiexperimental. Llegándose a la siguiente conclusión entre otras: que se encontraron diferencias significativas, es decir, que después del Programa de concientización jurídica, los estudiantes del grupo experimental sí desarrollaron avances significativos en el empoderamiento de los derechos humanos, en la IE Isaías Ardiles 7026 de Pachacámac.

Palabras clave: programa de concientización, empoderamiento, derechos humanos.

\section{ABSTRACT}

The purpose of this research is to establish the influence on the application of the Legal Awareness Program in the empowerment of Human Rights in Pachacámac, 2016. The general problem is: What is the influence of the application of the Legal Awareness Program in empowerment? of Human Rights in Pachacamác, 2016? His general hypothesis was: Yes, there is influence in the application of the Legal Awareness Program in the empowerment of Human Rights in Pachacamac, 2016. His approach was quantitative. The type of research was applied, the method of study was hypothetical deductive, its design was quasi-experimental. Reaching the following conclusion among others: significant differences were found, that is to say that after the Legal Awareness Program, the students of the experimental group did develop significant advances in the empowerment of Human Rights, in the IE Isaías Ardiles 7026 in Pachacámac.

Key words: awareness program, empowerment, human rights. 


\section{INTRODUCCIÓN}

Esta investigación sobre un programa de empoderamiento de concientización jurídica en derechos humanos a escolares del quinto de secundaria en el distrito de Pachacámac se realizó ante la deficiente información y formación sobre derechos humanos en educación básica. Por ello, se les aplicó un programa de concientización jurídica que permita al estudiante empoderarse sobre los derechos humanos de primera, segunda y tercera generación; es decir, a través de talleres de diálogo, sensibilización y debate se logró la información respectiva y la concientización jurídica de empoderamiento en dichos estudiantes.

En este programa hubo una metodología de enseñanza que combinó la teoría con la práctica, que tuvo como objetivo deducir y probar la hipótesis. Hubo un trabajo en equipo, o en grupo, donde cada estudiante jugó un rol importante que elevó su autoestima. Este programa dio ciertas herramientas muy específicas para pulir al estudiante en su personalidad, en la defensa y en el empoderamiento de los derechos humanos que aportaron a la formación y sobre todo al desarrollo del humanismo en cada estudiante de quinto de secundaria del colegio de Pachacámac.

El estudio, que se desarrolló en la Institución Educativa de Secundaria de Pachacámac, se graficó de la siguiente manera: se tuvo un aula de control con 25 estudiantes a quienes no se les aplicó ningún programa, o sea que sigue el método tradicional, y otra aula experimental a quienes si se les aplicó el programa de empoderamiento sobre derechos humanos. Al inicio del estudio se les tomó una prueba de entrada a las dos aulas, sobre la problemática planteada, donde no hubo diferencias sustantivas al respecto.

Concluido el programa de empoderamiento con el desarrollo de sus respectivas actividades, donde se hizo una buena planificación, se usó una correcta metodología y se utilizaron diversos materiales. El rol activo del estudiante fue la característica principal, y se demostró que en el aula experimental sí se desarrolló un avance significativo en derechos humanos de primera, segunda y tercera generación. Es así como se concluyó este estudio probándose la hipótesis: Sí, existe influencia en la aplicación del Programa de concientización jurídica en el empoderamiento de los derechos humanos en Pachacámac, 2016. 
En las principales universidades del país y muy en particular en las Facultades de Derecho y Ciencia Política hay asignaturas y diversas actividades sobre derechos humanos, pero se quedan solo en el ámbito académico, dentro del recinto universitario. No hay trabajos de investigación que en este aspecto se integren a la comunidad. Por ello es que con este estudio o investigación se llegó a sectores marginales del distrito de Pachacámac en el ámbito educativo del nivel básico, en este caso de secundaria. De la misma manera, en el Perú no existe una cultura de defensa y empoderamiento de los derechos humanos, hay un descuido no solo de las personas sino también de la misma sociedad, que con sus instituciones descuidan este aspecto fundamental del humanismo. Por ello se desarrolló esta investigación, ya que este trabajo es inédito sobre programas o talleres de empoderamiento sobre derechos humanos desarrollados en estudiantes, investigado en diseño cuasiexperimental. Ahora bien, el reconocimiento legal de los derechos humanos ha tenido una larga historia. Es en ese marco que podemos clasificar los derechos en grupos.

\begin{tabular}{|c|c|c|c|l|l|}
\hline $\begin{array}{c}\text { GENERACIÓN } \\
\text { DE DERECHOS }\end{array}$ & $\begin{array}{c}\text { ÉPOCA DE } \\
\text { ACEPTACIÓN }\end{array}$ & $\begin{array}{c}\text { TIPO DE } \\
\text { DERECHOS }\end{array}$ & $\begin{array}{c}\text { VALOR QUE } \\
\text { DEFIENDEN }\end{array}$ & FUNCIÓN PRINCIPAL & \multicolumn{1}{|c|}{ EJEMPLOS } \\
\hline Primera & $\begin{array}{c}\text { S. XVIII y } \\
\text { XIX }\end{array}$ & $\begin{array}{c}\text { Civiles y } \\
\text { políticos }\end{array}$ & LIBERTAD & $\begin{array}{l}\text { Limitar la acción } \\
\text { del poder. } \\
\text { Garantizar la } \\
\text { participación } \\
\text { política de los } \\
\text { ciudadanos. }\end{array}$ & $\begin{array}{l}\text { Derechos civiles: derecho a la vida, } \\
\text { a la libertad, a la seguridad, a la } \\
\text { propiedad... } \\
\text { Derechos políticos: derecho al } \\
\text { voto, a la asociación, a la huelga... }\end{array}$ \\
\hline Segunda & S. XIX y XX & $\begin{array}{c}\text { Económicos, } \\
\text { sociales y } \\
\text { culturales }\end{array}$ & IGUALDAD & $\begin{array}{l}\text { Garantizar unas } \\
\text { condiciones de } \\
\text { vida dignas para } \\
\text { todos }\end{array}$ & $\begin{array}{l}\text { Derecho a la salud, a la educación, } \\
\text { al trabajo, a una vivienda digna... }\end{array}$ \\
\hline Tercera & S. XXX XXXI & $\begin{array}{l}\text { Justicia, paz y } \\
\text { solidaridad }\end{array}$ & SOLIDARIDAD & $\begin{array}{l}\text { Promover } \\
\text { relaciones } \\
\text { pacíficas y } \\
\text { constructivas }\end{array}$ & $\begin{array}{l}\text { Derecho a un medio ambiente } \\
\text { limpio, a la paz, al desarrollo.... }\end{array}$ \\
\hline
\end{tabular}

Fuente: recursostic.educacion.es

Es en ese contexto que este estudio tiene como problema general: ¿cuál es la influencia de la aplicación del Programa de concientización jurídica en el empoderamiento de los derechos humanos en Pachacámac, 2016? Sus problemas específicos son: ¿cuál es la influencia de la aplicación del Programa de concientización jurídica en el empoderamiento de los derechos humanos de primera generación en Pachacámac, 2016?, ¿cuál es la influencia de la aplicación del Programa de concientización jurídica en el empoderamiento de los derechos humanos de segunda generación en Pachacámac, 2016? y ¿cuál es la influencia de la aplicación del Programa de concientización jurídica en el empoderamiento de los derechos humanos de tercera generación en Pachacámac, 2016? 
Los derechos humanos son derechos inherentes a todos los seres humanos, sin distinción alguna de nacionalidad, lugar de residencia, sexo, origen nacional o étnico, color, religión, lengua, o cualquier otra condición. Todos tenemos los mismos derechos humanos, sin discriminación alguna. Estos derechos son interrelacionados, interdependientes e indivisibles. ${ }^{1}$ Los derechos humanos universales están a menudo contemplados en la ley y garantizados por ella, a través de los tratados.

El principio de la universalidad de los derechos humanos es la piedra angular del Derecho Internacional de los Derechos Humanos. En la Conferencia Mundial de Derechos Humanos celebrada en Viena en 1993, por ejemplo, se dispuso que todos los Estados tuvieran el deber, independientemente de sus sistemas políticos, económicos y culturales, de promover y proteger todos los derechos humanos y las libertades fundamentales. Los derechos humanos son inalienables. No deben suprimirse, salvo en determinadas situaciones y según las debidas garantías procesales. Por ejemplo, se puede restringir el derecho a la libertad si un tribunal de justicia dictamina que una persona es culpable de haber cometido un delito.

Todos los derechos humanos, sean estos los derechos civiles y políticos, como el derecho a la vida, la igualdad ante la ley y la libertad de expresión; los derechos económicos, sociales y culturales, como el derecho al trabajo, la seguridad social y la educación; o los derechos colectivos, como los derechos al desarrollo y la libre determinación, todos son derechos indivisibles, interrelacionados e interdependientes. Los Estados asumen las obligaciones y los deberes, en virtud del derecho internacional, de respetar, proteger y realizar los derechos humanos.

La obligación de respetarlos significa que los Estados deben abstenerse de interferir en el disfrute de los derechos humanos, o de limitarlos.

La obligación de protegerlos exige que los Estados impidan los abusos de los derechos humanos contra individuos y grupos. La obligación de realizarlos significa que los Estados deben adoptar medidas positivas para facilitar el disfrute de los derechos humanos básicos. En el plano individual, así como debemos hacer respetar nuestros derechos humanos, también debemos respetar los derechos humanos de los demás (Naciones Unidas). ${ }^{2}$

1 Estas características se derivan de una concepción integral de los derechos, en los que no opera ninguna forma de jerarquía ni sus violaciones o consecuencias pueden tratarse aisladamente de otras en las que no se haya actuado en forma directa. Si la integridad se rompe, se afecta la persona como un todo y no solo una parte de ella. La indivisibilidad significa que todos los derechos humanos están unidos por un mismo cuerpo de principios y que todos están situados a un mismo nivel. No hay derechos humanos más importantes que otros.

2 Según la ONU, todos los Estados han ratificado al menos uno, y el 80 por ciento de ellos cuatro o más, de los principales tratados de derechos humanos, reflejando así el consentimiento de los Estados para establecer obligaciones jurídicas que se comprometen a cumplir, y confiriéndole al concepto de la universalidad una expresión concreta. Algunas normas fundamentales de derechos humanos gozan de protección universal en virtud del derecho internacional consuetudinario a través de todas las fronteras y civilizaciones. 
Sin embargo, la violación a un derecho social como la salud no desencadena el funcionamiento de ese sistema de derechos humanos tal como se describe. Dado el carácter programático de muchos de esos derechos, se torna ilusoria su exigibilidad frente el órgano de justicia interno o internacional. Deben lograr un "desarrollo progresivo", en la "medida de los recursos disponibles" (según las fórmulas estipuladas en los tratados). Por ello carecerían de "justiciabilidad".

Se debe dejar sentado que el hecho de que la justiciabilidad de los derechos económicos, sociales y culturales no sea una práctica corriente en nuestro país, no significa que aquellos, en algunos casos, no puedan exigirse judicialmente. Hay fuertes tendencias en ese sentido, y ya cierta jurisprudencia relevante. Principios como el de no discriminación o el debido proceso operan como combinación numérica ante el cerramiento del sistema judicial.

Sin embargo, el esfuerzo técnico por tornar justiciables los derechos económicos, sociales y culturales y por forzar cambios jurisdiccionales nos está demostrando que en la práctica hay serias diferencias entre las dos categorías de derechos y un fuerte sentimiento de no exigibilidad o realización de los económicos, sociales y culturales, que socavan el principio de su indivisibilidad. $^{3}$

En el Perú tenemos que la Constitución Política del Perú señala en su Artículo $1^{\circ}$ que la defensa de la persona humana y el respeto de su dignidad son el fin supremo de la sociedad y del Estado; téngase en cuenta que el Artículo $44^{\circ}$ de la Constitución Política del Perú señala como deber primordial del Estado garantizar la plena vigencia de los derechos humanos. Que la Cuarta Disposición Final y Transitoria de la Constitución Política del Perú dispone que las normas relativas a los derechos y a las libertades que la Constitución reconoce se interpretan de conformidad con la Declaración Universal de Derechos Humanos y con los tratados y acuerdos internacionales sobre las mismas materias ratificados por el Perú; así, en materia de cooperación, desarrollo y fortalecimiento de los derechos humanos, la Declaración y el Programa de Acción de Viena aprobados en la Conferencia Mundial de Derechos Humanos recomienda que cada Estado considere la posibilidad de elaborar un plan de acción nacional en el que se determinen las medidas necesarias para que ese Estado mejore la promoción y protección de los derechos humanos.

Esta invstigación tuvo como objetivos: Objetivo general: Establecer la influencia en la aplicación del Programa de concientización jurídica en el empoderamiento de los derechos humanos en Pachacámac, 2016. Como Objetivos específicos: Determinar la influencia en la aplicación del Programa de concientización jurídica en el empoderamiento de los derechos

3 Tomás Ojea Quintana, Reflexiones sobre la indivisibilidad de los derechos humanos: el problema de los derechos económicos, sociales y culturales, acceso el 26 de marzo de 2016, http://www.carlosmanzano.net/articulos/Ojeaquintana.html 
humanos de primera generación en Pachacámac, 2016. Determinar la influencia en la aplicación del Programa de concientización jurídica en el empoderamiento de los derechos humanos de segunda generación en Pachacámac, 2016. Determinar la influencia en la aplicación del Programa de concientización jurídica en el empoderamiento de los derechos humanos de tercera generación en Pachacámac, 2016.

Su hipótesis general fue: Sí, existe influencia en la aplicación del Programa de concientización jurídica en el empoderamiento de los derechos humanos en Pachacámac, 2016. Sus hipótesis específicas fueron: Sí, existe influencia de la aplicación del Programa de concientización jurídica en el empoderamiento de los derechos humanos de primera generación en Pachacámac, 2016. Sí, existe influencia de la aplicación del Programa de concientización jurídica en el empoderamiento de los derechos humanos de segunda generación en Pachacámac, 2016. Sí, existe influencia de la aplicación del Programa de concientización jurídica en el empoderamiento de los derechos humanos de tercera generación en Pachacámac, 2016.

Su variable independiente fue: Programa de concientización jurídica, y su variable dependiente fue: Empoderamiento en derechos humanos, y sus dimensiones fueron: derechos humanos de primera generación, derechos humanos de segunda generación y derechos humanos de tercera generación.

\section{MATERIALES Y METODOLOGÍA}

Para el desarrollo de las distintas actividades del Programa de concientización jurídica se utilizaron los siguientes materiales, como cartulina, tijeras, lana, bolígrafo o rotulador. También videos de Amnistía Internacional, textos donados por Amnistía Internacional, láminas a colores de casos reales sobre los problemas de derechos civiles, derechos a la salud y al medio ambiente o textos muy figurativos a colores cuyos contenidos son los derechos humanos de primera, segunda y tercera generación, explicados en los videos y en las sesiones que con lluvias de ideas se organizaron para empoderar al estudiante con un perfil humanístico que se desarrolló en el aula experimental. O también cuando cada estudiante debe pensar cuáles cree que son las 5 cosas sin las que una persona no puede vivir, y anotarlas en una tarjeta de cartulina, que previamente debe estar cortada por el profesor. Para luego colocarlas en un cordel, e ir colgando las tarjetas en la pared, o en la pizarra. Es así como ellos, los mismos estudiantes, van ordenando de acuerdo a las tarjetas los derechos humanos de primera, segunda y tercera generación.

El programa de derechos humanos que se desarrolló para los estudiantes estuvo compuesto por 12 sesiones que consignaron: derechos de primera generación (4 sesiones): derecho a la vida, a la libertad, a la seguridad, a la propiedad. Derechos políticos: derecho al voto, a la asociación, a la huelga. Derechos de segunda generación (4 sesiones): Derecho a la salud, a 
la educación, al trabajo, a una vivienda digna, etcétera. Por último tenemos derechos de la tercera generación (4 sesiones): derecho a un medio ambiente limpio, a la paz, al desarrollo de relaciones pacíficas.

En cuanto a la metodología del programa de Concientización jurídica, se apoya en la metodología activa, la cual se fundamenta en una estrategia pedagógica y didáctica de los derechos humanos, que promueve que el estudiante participe activamente del empoderamiento sobre derechos humanos, mediante recursos didácticos como debates, discusiones grupales y aprendizaje colaborativo, entre otros. En esta dinámica, el docente realiza un rol de guía facilitador, asesorando y acompañando al estudiante en su empoderamiento en derechos humanos.

La aplicación de este programa se desarrolló de la siguiente manera: Primero, se hizo dinámicas de grupos con el objetivo de desarrollar la inclusión de cada estudiante, las mismas que parten de la interiorización, relajación, reflexión y percepción personal, juegos que llevan a la reflexión sobre los derechos humanos basados en la propia experiencia, permitiendo una introducción del tema a desarrollar. Segundo: desarrollar la concepción de los estudiantes de quinto de secundaria acerca de la actividad o tema que se va a desarrollar; lluvia de ideas, pegado de conceptos en cartulinas de colores en la pared, etcétera. Todo ello permitió conocer su visión sobre los derechos humanos, juicios, prejuicios, y a partir de allí, analizar los diferentes puntos de vista y determinar cuáles son los conceptos más adecuados, generando propuestas desde el conocimiento estudiantil para el empoderamiento escolar, a través de intervenciones, trabajos grupales e individuales, exposiciones y confrontaciones, siendo importante el grado de participación de todos los estudiantes de quinto de secundaria. Tercero: Promoción e interiorización de las vivencias sobre como asimilar los derechos humanos en términos prácticos, tomando como referencia a las experiencias, anécdotas diversas, todo ello para el empoderamiento sobre los derechos humanos, hacer de los estudiantes protagonistas de la difusión y masificación de los conocimientos e información de los derechos humanos y sus 3 generaciones. También se les obsequió material bibliográfico donado por Amnistía Internacional.

Es en ese contexto que el tipo de investigación fue aplicada porque trató de resolver el problema planteado a partir de un programa. Su método fue deductivo e hipotético. El enfoque fue cuantitativo, y su diseño fue cuasiexperimental. Al esquematizar este tipo de investigación, obtenemos el siguiente diagrama:

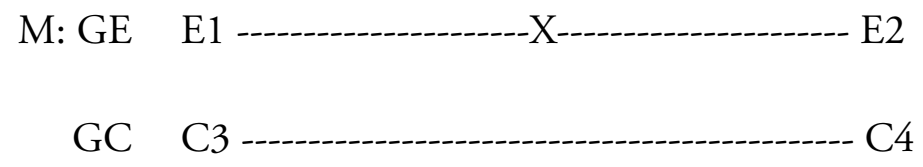


Donde:

M: Muestra de la investigación

GE E1: Pretest

E2: Postest

$\mathrm{X}$ : Programa de concientización jurídica

GC C3: Pretest

C4: Postest

Universo: La población o universo estuvo constituido por todos los estudiantes de quinto de secundaria: 2 aulas en la mańana y dos aulas en la tarde, equivalentes a 100 estudiantes.

Muestra: Constituido por 2 secciones aleatorias

\begin{tabular}{|c|c|}
\hline Sección & N \\
\hline A & 25 \\
\hline B & 25 \\
\hline Total & $\mathbf{5 0}$ \\
\hline
\end{tabular}

Se aplica el MIA (muestra aleatoria para proporciones)

Si el universo es finito, es decir, conocemos el total de la población y deseásemos saber cuántos del total tendremos que estudiar, la respuesta sería:

$$
n=\frac{N^{*} Z_{a}^{2} p^{*} q}{d^{2 *}(N-1)+Z_{a}^{2 *} p^{*} q}
$$

Dónde:

- $\quad \mathrm{N}=$ Total de la población

- $\quad \mathrm{Z}_{\mathrm{a}}^{2}=1,96^{2}$ (si la seguridad es del $95 \%$ )

- $\mathrm{p}=$ proporción esperada (en este caso $50 \%=0,5$ )

- $\quad \mathrm{q}=1-\mathrm{p}$ (en este caso $1-0,5=0,5)$

- $\mathrm{d}=$ precisión (en este caso deseamos un $5 \%$ ).

$$
n=\frac{103 * 1,96^{2} * 0,5 * 0,5 * 0,5}{0,50^{2} *(103-1)+1,96^{2} * 0,5 * 0,5}=50
$$


Aplicando el diseño muestral estratificado para proporciones se obtiene la siguiente muestra:

\begin{tabular}{|c|c|c|}
\hline Sección & N & Peso \\
\hline A & 25 & 0,24 \\
\hline B & 25 & 0,24 \\
\hline C & 25 & 0,24 \\
\hline D & 25 & 0,24 \\
\hline Total & $\mathbf{1 0 0}$ & $\mathbf{1}$ \\
\hline
\end{tabular}

Se seleccionarán 50 estudiantes aleatoriamente, 25 de la sección A, 25 de la sección $B$, (de control y experimental); las aulas C y D servirán para el pilotaje.

Instrumentos: El instrumento de recolección de datos debe reunir dos requisitos esenciales: validez, y confiabilidad. La validez: La validez del instrumento de los derechos humanos. Según Hernández Sampieri, "todo instrumento debe medir lo que se ha propuesto medir, vale decir que demuestre efectividad al obtener los resultados de la capacidad, conducta, rendimiento o aspecto que asegura medir", y también como dice Naupas P. y otros, "todo instrumento antes de ser aplicado en la recolección de datos debe reunir dos cualidades fundamentales: la validez y la confiabilidad".

Para determinar la validez de la encuesta sobre empoderamiento de los derechos humanos, se someterá a una evaluación, proporcionándoles a reconocidos profesionales de trayectoria universitaria ligada a las ciencias jurídicas y a la investigación. Sobre las encuestas a aplicarse a los educandos, la hoja de juicio de expertos y la matriz de consistencia, quienes determinarán la adecuación muestral de los ítems de los instrumentos, emitiendo su respectiva calificación.

Los resultados se muestran en el siguiente cuadro:

CUADRO 1. NIVEL DE VALIDEZ DE LA ENCUESTA SEGÚN EL JUICIO DE EXPERTOS

\begin{tabular}{|l|c|c|}
\hline \multirow{2}{*}{\multicolumn{1}{|c|}{ EXPERTOS }} & \multicolumn{2}{c|}{ Empoderamiento en derechos humanos } \\
\cline { 2 - 3 } & Puntaje & Porcentaje \\
\hline 1. Dra. Felipa Elvira Muñoz Ccuro & 770 & $89,0 \%$ \\
\hline 2. Dra. Zoila Irene González Farroñay & 810 & $91,0 \%$ \\
\hline 3. Mg. Viky Orbegoso Rivera & 755 & $87,0 \%$ \\
\hline 4. Mg. Víctor Daniel Hijar Hernández & 820 & $90,0 \%$ \\
\hline 5. Dr. Edwin Barrios Valer & 780 & $88,0 \%$ \\
\hline Promedio de valoración & $\mathbf{3 9 3 5}$ & $\mathbf{8 9 , 0} \%$ \\
\hline
\end{tabular}


La validez de los cuestionarios presentada por los expertos arroja un puntaje de 3935 que corresponde a $87,4 \%$.

Los valores resultantes después de tabular la calificación emitida por los expertos están comprendidos en el siguiente cuadro:

CUADRO 2. VALORES DE LOS NIVELES DE VALIDEZ

\begin{tabular}{|c|c|}
\hline VALORES & NIVELES DE VALIDEZ \\
\hline $91-100$ & Excelente \\
\hline $81-90$ & Muy bueno \\
\hline $71-80$ & Bueno \\
\hline $61-70$ & Regular \\
\hline $51-60$ & Deficiente \\
\hline
\end{tabular}

De acuerdo a la tabla de valores, el concepto de validación otorgado por los jueces es de un $87,4 \%$, es decir, la categorización de la encuesta tiene muy buena validez.

\section{Confiabilidad de los instrumentos}

Para la determinación de la confiabilidad de los instrumentos se siguieron los siguientes pasos.

a. Para determinar el grado de confiabilidad de las encuestas sobre derechos humanos, primero se determinó una muestra piloto de veinte educandos del colegio, lo cual permitió determinar el grado de confiabilidad.

b. Luego, se estimó el coeficiente de confiabilidad de las encuestas sobre derechos humanos. Se aplicó el alpha de Crombach que muestra el siguiente resultado de:

c.

\section{ESTADÍSTICOS DE FIABILIDAD}

\begin{tabular}{|c|c|}
\hline Alfa de Crombach & $\mathbf{N}^{\circ}$ de elementos \\
\hline 0,988 & 26 \\
\hline
\end{tabular}

Se entiende que el alfa mínimo aceptable debe estar alrededor de 0,70 y para instrumentos que requieren ser muy certeros se recomienda no menos de 0,988 . 
Valores de niveles de confiabilidad

\begin{tabular}{|c|c|}
\hline Valores & Nivel de confiabilidad \\
\hline 0,53 a menos & Confiabilidad nula \\
\hline 0,54 a 0,59 & Confiabilidad baja \\
\hline 0,60 a 0,65 & Confiable \\
\hline 0,66 a 0,771 & Muy confiable \\
\hline 0,72 a 0,99 & Excelente confiabilidad \\
\hline 1,0 & Confiabilidad perfecta \\
\hline
\end{tabular}

Fuente: Hernández Sampieri, Roberto (2006).

En la aplicación de los instrumentos sobre derechos humanos se obtuvo el valor de 0,988. Según esta escala, podemos deducir que la encuesta tiene una excelente confiabilidad.

\section{CUESTIONARIO 01}

1 El derecho a la vida es amparado desde:
a) La concepción
b) El noviazgo
c) El nacimiento

2 Constituye un derecho de primera generación:
a) La vida
b) El trabajo
c) La paz

3 El reconocimiento de los derechos humanos se sustenta en una concepción según la cual estos son:
a) La vida
b) El trabajo
c) La paz

4 Se dice que una persona tiene derechos porque:
a) Obedece a su naturaleza humana
b) Los derechos sociales
c) Es parte de la Ley 
5 ¿Qué establece la Declaración Universal de los Derechos Humanos con respecto a la detención arbitraria de la persona?

a) Nadie podrá ser arbitrariamente detenido, preso ni desterrado

b) Solamente por 24 horas

c) Solo por la PNP

6 Distingue cuál de las garantías constitucionales debe interponer ante el juez, una persona que es detenida sin orden del juez o de la Policía Nacional:
a) Hábeas corpus
b) Hábeas data
c) Acción de amparo

7 El ejercicio de la ciudadanía se suspende por:
a) Proceso judicial con detención efectiva
b) Por pérdida del DNI
c) Por mayoría de edad

8 La vigente Constitución Política del Perú determina que el fin supremo de la sociedad y del Estado es la defensa de:
a) La persona humana y su dignidad
b) La salud
c) El trabajo

9 La Constitución Política protege, prioritariamente:
a) Los derechos fundamentales
b) La sociedad
c) Los poderes del Estado.

10 El derecho que tiene una persona para usar, gozar y disponer de un bien sin perjuicio de la colectividad, se refiere a:
a) Derecho de propiedad
b) Derecho al trabajo
c) Derecho a la salud

11 Órgano Constitucional autónomo del Estado Peruano encargado de proteger los derechos constitucionales y fundamentales de la persona y comunidad:
a) La defensoría del pueblo
b) La ONPE
c) El RENIEC 
12 El derecho a tener una atención de salud por parte del Estado es imprescindible para el desarrollo de la sociedad. Esta afirmación corresponde a:
a) Derecho a la salud
b) Derecho al trabajo
c) Derecho a la libertad

13 La salud como condición indispensable del desarrollo humano y medio fundamental para alcanzar el bienestar individual y colectivo pertenece a un derecho de:
a) Primera generación
b) Segunda generación
c) Tercera generación

14 Según la Constitución, la educación tiene por finalidad:
a) La formación integral del ser humano
b) La instrucción de los estudiantes
c) El desarrollo académico.

15 ¿Cómo considera la Declaración de los Derechos Humanos a la educación?
a) Toda persona tiene derecho a la educación, la misma que debe ser gratuita
b) Es privilegio de algunos
c) Es cultura nacional.

16 La Constitución determina que el trabajo es:
a) Un deber y un derecho
b) Un deber
c) Un derecho

17 Los derechos relacionados con el trabajo, seguridad social, salud y educación son denominados de:
a) Primera generación
b) Segunda generación
c) Tercera generación

18 El Estado garantiza a los pobladores el poseer una vivienda digna. ¿Cree que esta afirmación se cumple en nuestra sociedad?
a) Sí
b) No 
19 ¿Existen programas de vivienda impulsados por el Estado? ¿Conoce alguno de ellos?
a) Sí
b) No

20 El uso del internet, se constituye en un fin social; las municipalidades tienen la obligación de proveer de este servicio a los vecinos. ¿¿Cree que esta disposición se cumple?
a) Sí
b) No

21 ¿En tu localidad existen parques o lugares públicos donde el WiFi es de libre disponibilidad?
a) Sí
b) No

22 La alimentación de los nińos constituye una política de Estado, por consiguiente, el Estado peruano tiene la obligación de velar por su cumplimiento. ¿Cree usted que esto se cumple irrestrictamente?
a) Sí
b) $\mathrm{No}$

23 ¿En las instituciones educativas existen nutricionistas que velen por la adecuada alimentación de los estudiantes?
a) Sí
b) No

24 La Constitución Política señala que la célula básica de la sociedad y el Estado es:
a) La familia
b) La persona humana
c) El matrimonio

25 ¿Existe algún patrimonio cultural en tu localidad?
a) Sí
b) $\mathrm{No}$

26 ¿Cómo calificarías a tus amigos que se compadecen del sufrimiento ajeno, que les gusta ayudar a los demás?
a) Solidarios
b) Responsables
c) Respetuosos 


\section{RESULTADOS, TABLAS Y GRÁFICOS}

Prueba T Student para muestras pareadas en el grupo de control

\section{TABLA1.COMPARACIÓN DE LAMEDIA DEL PUNTAJEEN DERECHOS HUMANOS DE PRIMERA GENERACIÓN EN EL GRUPO DE CONTROL DE LOS ESTUDIANTES DE $5^{\circ}$ AÑO DE SECUNDARIA DE LA IE ISAÍAS ARDILES, 7026}

\begin{tabular}{|c|c|c|c|c|c|}
\hline & $\mathbf{N}$ & Media & $\begin{array}{c}\text { Desviación } \\
\text { estándar }\end{array}$ & $\mathbf{T}$ & $\mathbf{P}$ \\
\hline Inicio & 25 & 4,1 & 4,2 & \multirow{2}{*}{$-1,8$} & \multirow{2}{*}{$0,08^{*}$} \\
\hline Final & 25 & 4,2 & 4,1 & & \\
\hline
\end{tabular}

${ }^{*} \mathrm{P}=0,08>0,05$ no existe diferencia significativa.

T: Student para muestras pareadas.

Valor mínimo: $0 \quad$ Valor máximo: 20

De la tabla se observa que la media del puntaje en derechos humanos de primera generación al inicio en el grupo de control es $4.1 \pm 4.2$, y la media del puntaje en derechos humanos de primera generación al final en el grupo de control es 4,2 $\pm 4,1$. No se encontró diferencia significativa $\mathrm{P}>0,05$.

FIGURA 1. LA MEDIA EN DERECHOS HUMANOS DE PRIMERA GENERACIÓN AL INICIO EN EL GRUPO DE CONTROL ES 4,1 $\pm 4,2$, Y LA MEDIA EN DERECHOS HUMANOS DE PRIMERA GENERACIÓN AL FINAL EN EL GRUPO DE CONTROL

ES 4,2 $\pm 4,1$. NO HAY DIFERENCIAS SIGNIFICATIVAS

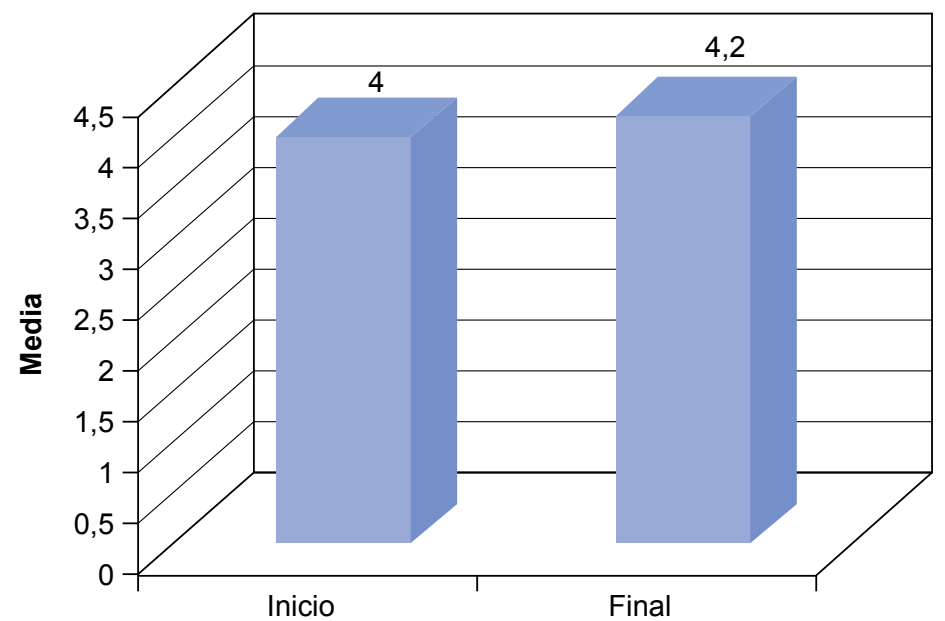


TABLA 2. COMPARACIÓN DE MEDIAS DEL PUNTAJE EN DERECHOS HUMANOS DE SEGUNDA GENERACIÓN AL INICIO Y FINAL EN EL GRUPO DE CONTROL DE LOS ESTUDIANTES DE $5^{\circ}$ AÑO DE SECUNDARIA DE LA IE ISAÍAS ARDILES, 7026

\begin{tabular}{|c|c|c|c|c|c|}
\hline & N & Media & $\begin{array}{c}\text { Desviación } \\
\text { estándar }\end{array}$ & T & P \\
\hline Inicio & 25 & 2,3 & 2,1 & \multirow{2}{*}{$-1,4$} & $0,16^{*}$ \\
\cline { 1 - 4 } Final & 25 & 2,4 & 2 & \\
\hline
\end{tabular}

${ }^{*} \mathrm{P}=0,16>0,05$ no existe diferencia significativa.

T: Student para muestras pareadas.

Valor mínimo: 0 Valor máximo: 10

De la tabla se observa que la media del puntaje en derechos humanos de segunda generación al inicio en el grupo de control es $2,3 \pm 2,1$, y la media del puntaje en derechos humanos de segunda generación al final en el grupo de control es $2,4 \pm 2$. No se encontró diferencia significativa $\mathrm{P}>0,05$.

FIGURA 2. LA MEDIA EN DERECHOS HUMANOS DE SEGUNDA GENERACIÓN AL INICIO EN EL GRUPO DE CONTROL ES 2,3 $\pm 2,1$, Y LA MEDIA DEL PUNTAJE EN DERECHOS HUMANOS DE SEGUNDA GENERACIÓN AL FINAL EN EL GRUPO DE CONTROL ES 2,4 \pm 2 . NO HAY DIFERENCIA SIGNIFICATIVA

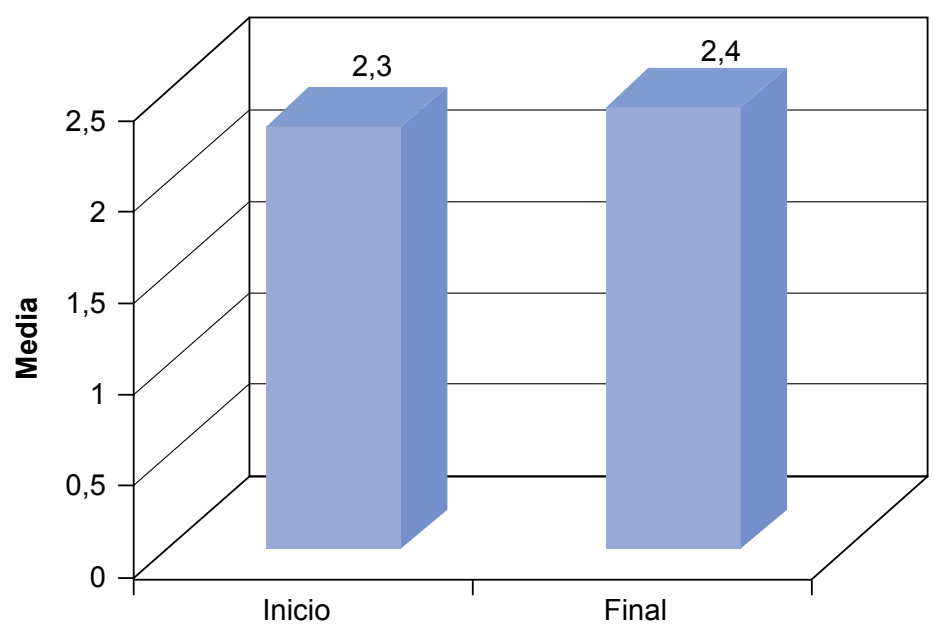


TABLA 3. COMPARACIÓN DE MEDIAS DEL PUNTAJE EN DERECHOS HUMANOS DE TERCERA GENERACIÓN AL INICIO Y FINAL EN EL GRUPO DE CONTROL DE LOS ESTUDIANTES DE $5^{\circ}$ AÑO DE SECUNDARIA DE LA IE ISAÍAS ARDILES, 7026

\begin{tabular}{|c|c|c|c|c|c|}
\hline & N & Media & $\begin{array}{c}\text { Desviación } \\
\text { estándar }\end{array}$ & $\mathbf{T}$ & $\mathbf{P}$ \\
\hline Inicio & 25 & 3,2 & 2,5 & \multirow{2}{*}{$-1,4$} & \multirow{2}{*}{$0,16^{*}$} \\
\cline { 1 - 3 } Final & 25 & 3,1 & 2,5 & & \\
\hline
\end{tabular}

${ }^{*} \mathrm{P}=0,16>0,05$ no existe diferencia significativa.

T: Student para muestras pareadas.

Valor mínimo: 0 Valor máximo: 10

De la tabla se observa que la media del puntaje en derechos humanos de tercera generación al inicio en el grupo control es 3,2 $\pm 2,5$, y la media del puntaje en derechos humanos de tercera generación al final en el grupo de control es $3,1 \pm 2,5$. No se encontró diferencia significativa $\mathrm{P}>0,05$.

FIGURA 3. LA MEDIA EN DERECHOS HUMANOS AL INICIO EN EL GRUPO CONTROL ES 3,2 $\pm 2,5$, Y LA MEDIA DEL PUNTAJE EN DERECHOS HUMANOS DE TERCERA GENERACIÓN AL FINAL EN EL GRUPO CONTROL ES 3,1 $\pm 2,5$. NO HAY DIFERENCIA SIGNIFICATIVA

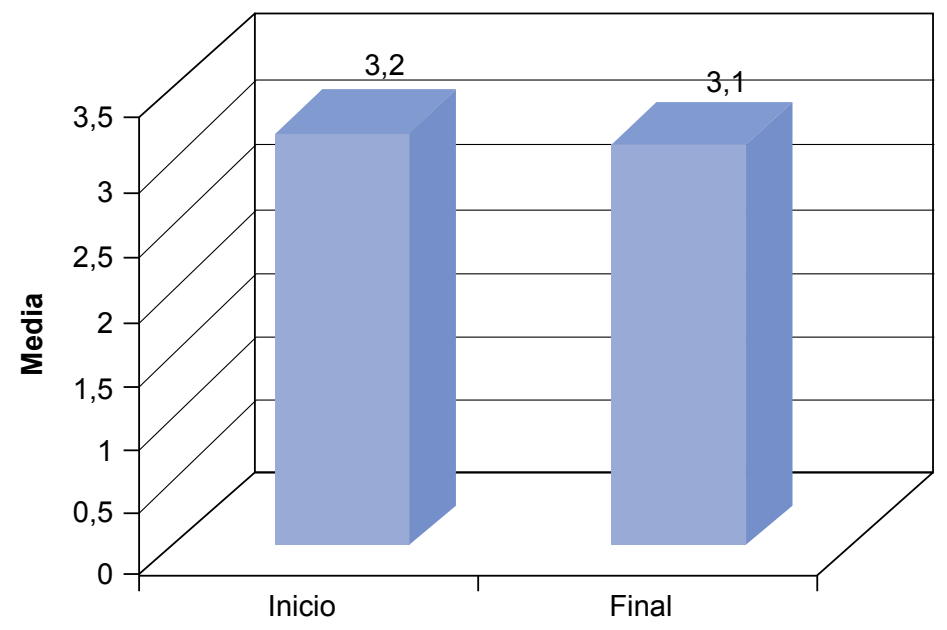




\begin{abstract}
TABLA 4.COMPARACIÓN DE MEDIAS DEL PUNTAJE EN DERECHOS HUMANOS AL INICIO Y FINAL EN EL GRUPO DE CONTROL DE LOS ESTUDIANTES DE $5^{\circ}$ AÑO DE SECUNDARIA DE LA IE ISAÍAS ARDILES, 7026
\end{abstract}

\begin{tabular}{|c|c|c|c|c|c|}
\hline & N & Media & $\begin{array}{c}\text { Desviación } \\
\text { estándar }\end{array}$ & T & P \\
\cline { 1 - 3 } Inicio & 25 & 9,6 & 6,8 & \multirow{2}{*}{$-0,33$} & $0,74^{*}$ \\
\cline { 1 - 3 } Final & 25 & 9,6 & 6,7 & \\
\hline
\end{tabular}

${ }^{*} \mathrm{P}=0,74>0,05$ no existen diferencias significativas.

T: Student para muestras pareadas.

Valor mínimo: 0 Valor máximo: 40

De la tabla se observa que la media del puntaje en empoderamiento de los derechos al inicio en el grupo de control es $9,6 \pm 6,8$, y la media del puntaje en comunicación al final en el grupo de control es 9,6 $\pm 6,7$. No hay diferencia significativa $P>0,05$.

FIGURA 4. LA MEDIA EN DERECHOS HUMANOS AL INICIO EN EL GRUPO DE CONTROL ES $9,6 \pm 6,8$, Y LA MEDIA DEL PUNTAJE EN LOS DERECHOS HUMANOS

AL FINAL EN EL GRUPO DE CONTROL ES $9,6 \pm 6,7$. NO HAY DIFERENCIA SIGNIFICATIVA.

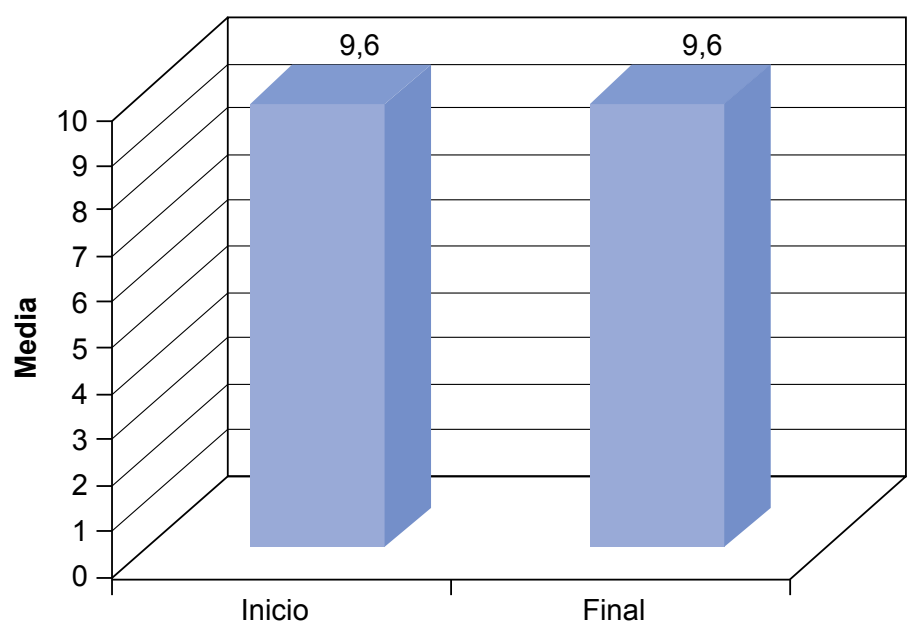


Prueba T student para muestras pareadas en el grupo experimental TABLA 5. COMPARACIÓN DE MEDIAS DEL PUNTAJE EN DERECHOS HUMANOS DE
PRIMERA GENERACIÓN AL INICIO Y FINAL EN EL GRUPO EXPERIMENTAL DE LOS
ESTUDIANTES DE $5^{\circ}$ AÑO DE SECUNDARIA DE LA IE ISAÍAS ARDILES, 7026

\begin{tabular}{|c|c|c|c|c|c|}
\hline & N & Media & $\begin{array}{c}\text { Desviación } \\
\text { estándar }\end{array}$ & T & P \\
\hline Inicio & 25 & 5,3 & 3,7 & $-9,36$ & $0,0000^{*}$ \\
\hline Final & 25 & 14 & 2,9 & & \\
\hline
\end{tabular}

${ }^{*} P=0,0000<0,05$ existen diferencias significativas.

T: Student para muestras pareadas.

Valor mínimo: 0 Valor máximo: 20

De la tabla se observa que la media del puntaje en derechos humanos de primera generación al inicio en el grupo de control es 5,3 $\pm 3,7$, y la media del puntaje en derechos humanos de primera generación al final en el grupo experimental es $14 \pm 2,9$. Se encontró diferencia significativa $\mathrm{P}<0,05$, es decir que después del Programa de concientización jurídica los estudiantes desarrollaron avances en la concientización en la dimensión derechos humanos de primera generación.

FIGURA 5. LA MEDIA EN DERECHOS HUMANOS DE PRIMERA GENERACIÓN AL INICIO EN EL GRUPO EXPERIMENTAL ES 5,3 $\pm 3,7$, Y LA MEDIA EN DERECHOS HUMANOS DE PRIMERA GENERACIÓN AL FINAL EN EL GRUPO EXPERIMENTAL ES $14 \pm 2,9$. HAY DIFERENCIA SIGNIFICATIVA DESPUÉS DEL PROGRAMA DE CONCIENTIZACIÓN JURÍDICA

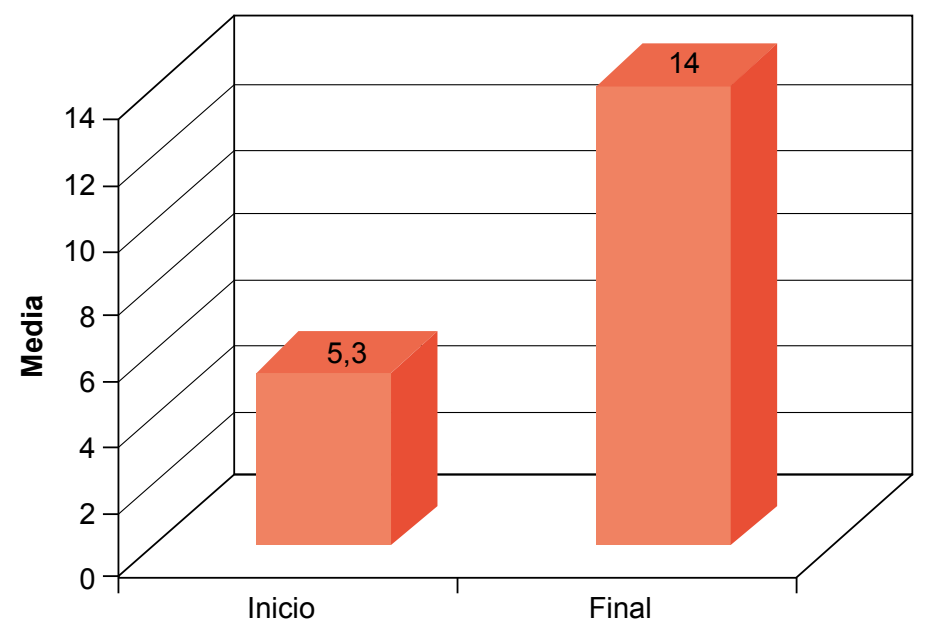


TABLA 6. COMPARACIÓN DE MEDIAS DEL PUNTAJE EN DERECHOS HUMANOS DE SEGUNDA GENERACIÓN AL INICIO Y FINAL EN EL GRUPO EXPERIMENTAL DE LOS ESTUDIANTES DE $5^{\circ}$ AÑO DE SECUNDARIA DE LA IE ISAÍAS ARDILES, 7026

\begin{tabular}{|c|c|c|c|c|c|}
\hline & N & Media & $\begin{array}{c}\text { Desviación } \\
\text { estándar }\end{array}$ & $\mathbf{T}$ & $\mathbf{P}$ \\
\hline Inicio & 25 & 2,8 & 2 & \multirow{2}{*}{$-8,39$} & \multirow{2}{*}{$0,0000^{*}$} \\
\hline Final & 25 & 6,9 & 1,9 & & \\
\hline
\end{tabular}

${ }^{*} \mathrm{P}=0,0000<0,05$ existen diferencias significativas.

T: Student para muestras pareadas.

Valor mínimo: 0 Valor máximo: 10

De la tabla se observa que la media del puntaje en derechos humanos de segunda generación en el grupo experimental es 2,8 \pm 2 y la media del puntaje en derechos humanos de segunda generación al final en el grupo experimental es 6,9 $\pm 1,9$. Se encontró diferencia significativa $\mathrm{P}<0,05$, es decir que después del Programa de concientización jurídica los estudiantes desarrollaron avances en la concientización jurídica en la dimensión de derechos humanos de segunda generación.

FIGURA 6. LA MEDIA EN DERECHOS HUMANOS DE SEGUNDA GENERACIÓN AL INICIO EN EL GRUPO EXPERIMENTAL ES DE 2,8 \pm 2 , Y LA MEDIA EN DERECHOS HUMANOS DE SEGUNDA GENERACIÓN ALFINALEN EL GRUPO EXPERIMENTALES 6,9 1,9. SE ENCONTRÓ DIFERENCIASIGNIFICATIVA DESPUÉS DEL PROGRAMADE CONCIENTIZACIÓN JURÍDICA

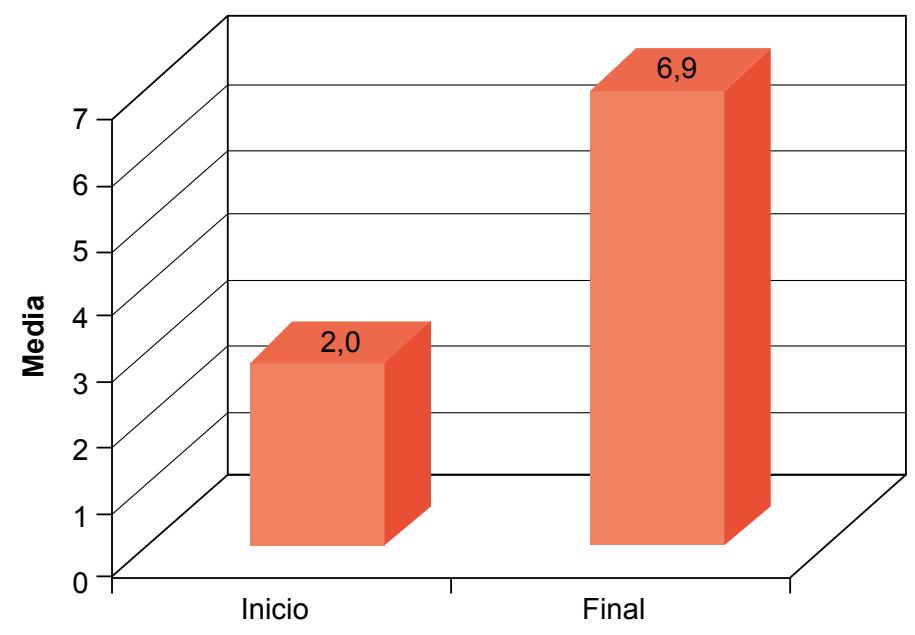


TABLA 7. COMPARACIÓN DE MEDIAS DEL PUNTAJE EN DERECHOS HUMANOS DE TERCERA GENERACIÓN AL INICIO Y FINAL EN EL GRUPO EXPERIMENTAL DE LOS ESTUDIANTES DE $5^{\circ}$ AÑO DE SECUNDARIA DE LA IE ISAÍAS ARDILES, 7026

\begin{tabular}{|c|c|c|c|c|c|}
\hline & N & Media & $\begin{array}{c}\text { Desviación } \\
\text { estándar }\end{array}$ & $\mathbf{T}$ & $\mathbf{P}$ \\
\hline Inicio & 25 & 2,6 & 1,9 & \multirow{2}{*}{$-12,46$} & \multirow{2}{*}{$0,0000^{*}$} \\
\cline { 1 - 4 } Final & 25 & 8 & 1,8 & & \\
\hline
\end{tabular}

${ }^{*} \mathrm{P}=0,000<0,05$ existen diferencias significativas.

T: Student para muestras pareadas.

Valor mínimo: 0 Valor máximo: 10

De la tabla se observa que la media del puntaje en derechos humanos de tercera generación al inicio en el grupo experimental es 2,6 $\pm 1,9$, y la media del puntaje en derechos humanos de tercera generación al final en el grupo experimental es $8 \pm 1,8$. Se encontró diferencia significativa $\mathrm{P}<0,05$, es decir que después del Programa de concientización jurídica los estudiantes desarrollaron avances en la concientización jurídica en la dimensión derechos humanos de tercera generación.

FIGURA 7. LA MEDIA EN DERECHOS HUMANOS DE TERCERA GENERACIÓN AL INICIO EN EL GRUPO EXPERIMENTAL ES 2,6 $\pm 1,9$, Y LA MEDIA EN DERECHOS HUMANOS DE TERCERA GENERACIÓN AL FINALEN EL GRUPO EXPERIMENTALES $8 \pm 1,8$. SE ENCONTRÓ DIFERENCIA SIGNIFICATIVA DESPUÉS DEL PROGRAMA DE CONCIENTIZACIÓN JURÍDICA

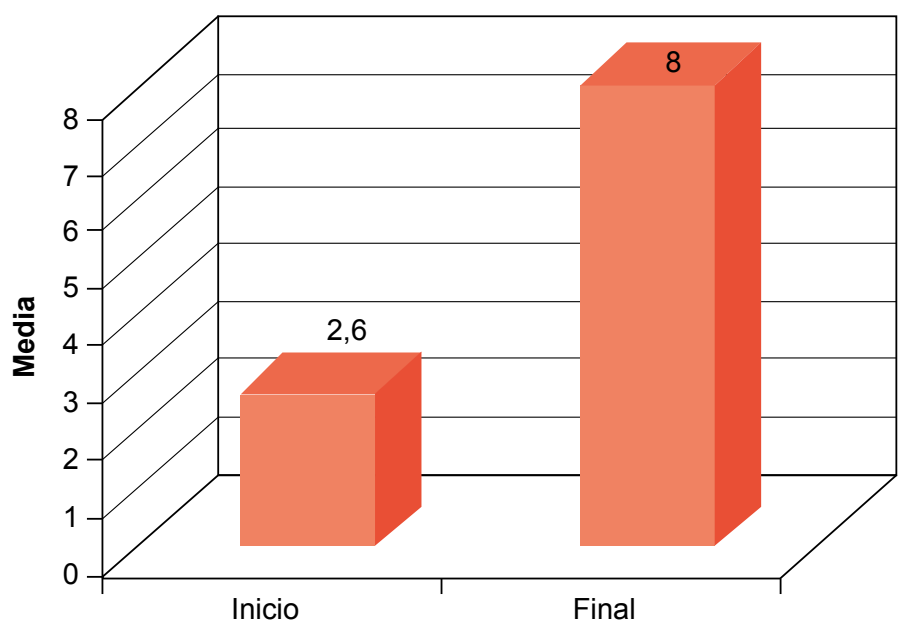


TABLA 8. COMPARACIÓN DE MEDIAS DEL PUNTAJE EN DERECHOS HUMANOS AL INICIO Y FINAL EN EL GRUPO EXPERIMENTAL DE LOS ESTUDIANTES DE $5^{\circ}$ AÑO DE SECUNDARIA DE LA IE ISAÍAS ARDILES, 7026

\begin{tabular}{|c|c|c|c|c|c|}
\hline & N & Media & $\begin{array}{c}\text { Desviación } \\
\text { estándar }\end{array}$ & T & P \\
\hline Inicio & 25 & 10,8 & 6,2 & \multirow{2}{*}{$-14,97$} & $0,0000^{*}$ \\
\cline { 1 - 4 } Final & 25 & 29 & 3,8 & & \\
\hline
\end{tabular}

${ }^{*} \mathrm{P}=0,0000<0,05$ existen diferencias significativas.

T: Student para muestras pareadas.

Valor mínimo: 0 Valor máximo: 40

De la tabla se observa que la media del puntaje en empoderamiento en derechos humanos al inicio en el grupo experimental es $10,8 \pm 6,2$, y la media del puntaje en empoderamiento en derechos humanos al final en el grupo experimental es $29 \pm 3,8$. Se encontró diferencia significativa $\mathrm{P}<0,05$, es decir que después del Programa de concientización jurídica, los estudiantes desarrollaron avance en la concientización del empoderamiento jurídico de los derechos humanos.

FIGURA 8. LA MEDIA EN DERECHOS HUMANOS AL INICIO EN EL GRUPO EXPERIMENTAL ES 10,8 $\pm 6,2$, Y LA MEDIA EN EMPODERAMIENTO EN DERECHOS HUMANOS AL FINAL EN EL GRUPO EXPERIMENTAL ES $29 \pm 3,8$. HAY DIFERENCIA SIGNIFICATIVA DESPUÉS DE LA CAPACITACIÓN JURÍDICA

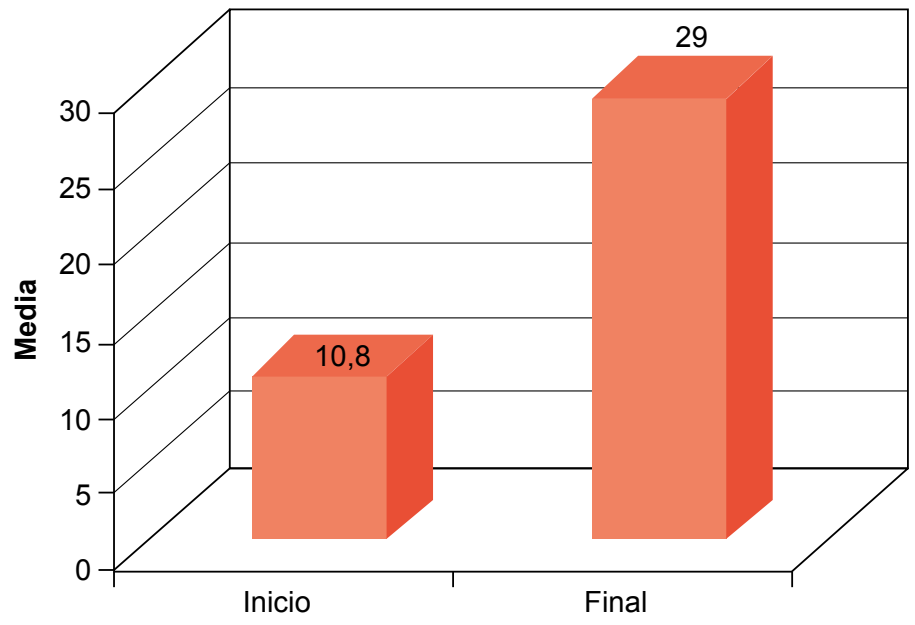


Prueba T Student para muestras independientes al final del taller en el grupo de control y grupo experimental

TABLA 9. COMPARACIÓN DE MEDIAS DEL PUNTAJE EN DERECHOS HUMANOS DE PRIMERA GENERACIÓN ENTRE EL GRUPO DE CONTROL Y EL GRUPO EXPERIMENTAL, AL FINAL DEL PROGRAMA DE CONCIENTIZACIÓN JURÍDICA, TALLER DE LOS ESTUDIANTES DE $5^{\circ}$ AÑO DE SECUNDARIA DE LA IE ISAÍAS ARDILES, 7026

\begin{tabular}{|c|c|c|c|c|c|}
\hline & N & Media & $\begin{array}{c}\text { Desviación } \\
\text { estándar }\end{array}$ & T & P \\
\hline Control & 25 & 4 & 4 & \multirow{2}{*}{$-9,82$} & $00,0000^{*}$ \\
\hline Experimental & 25 & 14 & 2,9 & & \\
\hline
\end{tabular}

${ }^{*} \mathrm{P}=0,0000<0,05$ existen diferencias significativas.

T: Student para muestras pareadas.

Valor mínimo: 0 Valor máximo: 20

De la tabla se observa que la media del puntaje en derechos humanos de primera generación entre el grupo de control es $4 \pm 4$, y el grupo experimental es $14 \pm 2$,9. Se encontró diferencia significativa $\mathrm{P}<0,05$, es decir, después del Programa de concientización jurídica los estudiantes del grupo experimental sí desarrollaron avance significativo en la concientización jurídica en la dimensión derechos humanos de primera generación.

FIGURA 9. LA MEDIA EN DERECHOS HUMANOS DE PRIMERA GENERACIÓN, ENTRE EL GRUPO DE CONTROL ES $4 \pm 4$, Y EL GRUPO EXPERIMENTAL ES $14 \pm$ 2,9. SE ENCONTRÓ DIFERENCIA SIGNIFICATIVA DESPUÉS DEL PROGRAMA DE CONCIENTIZACIÓN JURÍDICA

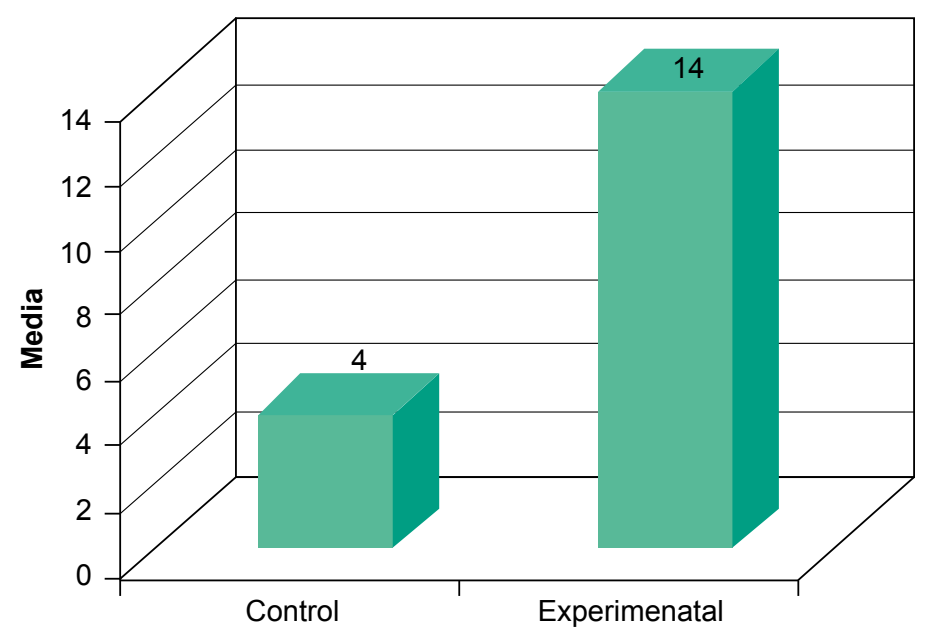


TABLA 10. COMPARACIÓN DE MEDIAS DEL PUNTAJE EN DERECHOS HUMANOS DE SEGUNDA GENERACIÓN, ENTRE EL GRUPO DE CONTROL Y EL GRUPO EXPERIMENTAL, AL FINAL DEL PROGRAMA DE CONCIENTIZACIÓN JURÍDICA DE LOS ESTUDIANTES DE $5^{\circ}$ AÑO DE SECUNDARIA DE LA IE 7026

\begin{tabular}{|c|c|c|c|c|c|}
\hline & N & Media & $\begin{array}{c}\text { Desviación } \\
\text { estándar }\end{array}$ & $\mathbf{T}$ & $\mathbf{P}$ \\
\hline Control & 25 & 2,4 & 2 & \multirow{2}{*}{-8} & $0,0000^{*}$ \\
\cline { 1 - 4 } Experimental & 25 & 6,9 & 1,9 & & \\
\hline
\end{tabular}

${ }^{*} \mathrm{P}=0,0000<0,05$ existe diferencias significativas.

T: Student para muestras pareadas.

Valor mínimo: $0 \quad$ Valor máximo: 10

De la tabla se observa que la media del puntaje en derechos humanos de segunda generación, entre el grupo de control es $2,4 \pm 2$, y el grupo experimental es $6.9 \pm 1$.9. Se encontró diferencia significativa $\mathrm{P}<0,05$, es decir que después del Programa de concientización jurídica del grupo experimental sí desarrollaron avance significativo en la concientización jurídica en la dimensión derechos humanos de segunda generación.

FIGURA 10. LA MEDIA EN DERECHOS HUMANOS DE SEGUNDA GENERACIÓN, ENTRE EL GRUPO DE CONTROL ES 2,4 22 Y EL GRUPO EXPERIMENTAL ES $6,9 \pm 1,9$. HAY DIFERENCIA SIGNIFICATIVA DESPUÉS DEL PROGRAMA DE CONCIENTIZACIÓN JURÍDICA

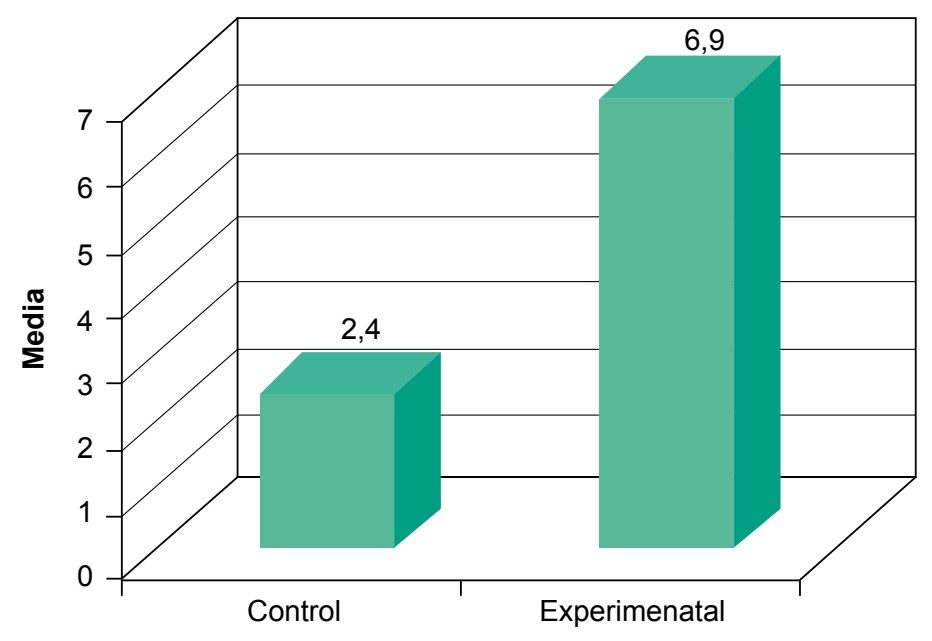




\begin{abstract}
TABLA 11.COMPARACIÓN DE MEDIAS DEL PUNTAJE EN DERECHOS HUMANOS
DE TERCERA GENERACIÓN, ENTRE EL GRUPO DE CONTROL Y EL GRUPO

EXPERIMENTAL, AL FINAL DEL PROGRAMA DE CONCIENTIZACIÓN JURÍDICA

EN LOS ESTUDIANTES DE $5^{\circ}$ AÑO DE SECUNDARIA DE LA IE 7026
\end{abstract}

\begin{tabular}{|c|c|c|c|c|c|}
\hline & N & Media & $\begin{array}{c}\text { Desviación } \\
\text { estándar }\end{array}$ & T & P \\
\hline Control & 25 & 3 & 2,5 & \multirow{2}{*}{$-8,06$} & $0,0000^{*}$ \\
\cline { 1 - 4 } Experimental & 25 & 8 & 1,8 & \\
\hline
\end{tabular}

${ }^{*} \mathrm{P}=0,000<0,05$ existen diferencias significativas.

T: Student para muestras pareadas.

Valor mínimo: $0 \quad$ Valor máximo: 10

De la tabla se observa que la media del puntaje en derechos humanos de tercera generación entre el grupo de control es $3 \pm 2,5$, y el grupo experimental es $8 \pm 1,8$. Se encontró diferencia significativa $\mathrm{P}<0,05$, es decir que después del Programa de concientización jurídica los estudiantes del grupo experimental sí desarrollaron avance significativo en la concientización jurídica en la dimensión derechos humanos de segunda generación.

\title{
FIGURA 11. LA MEDIA EN DERECHOS HUMANOS DE TERCERA GENERACIÓN ENTRE EL GRUPO DE CONTROL ES $3 \pm 2,5$, Y EL GRUPO EXPERIMENTAL ES $8 \pm 1,8$. SE ENCONTRÓ DIFERENCIA SIGNIFICATIVA DESPUÉS DEL PROGRAMA DE CONCIENTIZACIÓN JURÍDICA
}

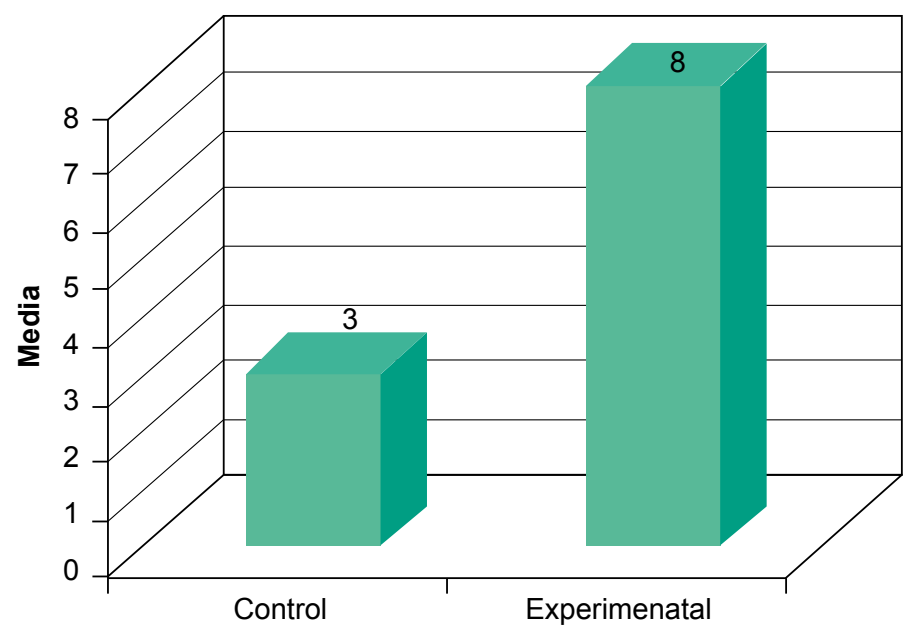


TABLA 12. COMPARACIÓN DE MEDIAS DEL PUNTAJE EN DERECHOS HUMANOS ENTRE EL GRUPO DE CONTROL Y EL GRUPO EXPERIMENTAL, AL FINAL DEL PROGRAMA DE CONCIENTIZACIÓN JURÍDICA EN LOS ESTUDIANTES DE 5 AÑO DE SECUNDARIA DE LA IE 7026

\begin{tabular}{|c|c|c|c|c|c|}
\hline & N & Media & $\begin{array}{c}\text { Desviación } \\
\text { estándar }\end{array}$ & T & P \\
\hline Control & 25 & 9,6 & 6,6 & \multirow{2}{*}{$-12,7$} & $0,0000^{*}$ \\
\cline { 1 - 4 } Experimental & 25 & 29 & 3,8 & & \\
\hline
\end{tabular}

${ }^{*} \mathrm{P}=0,0000<0,05$ existen diferencias significativas.

T: Student para muestras pareadas.

Valor mínimo: $0 \quad$ Valor máximo: 40

De la tabla se observa que la media del puntaje en empoderamiento en derechos humanos entre en el grupo de control es 9,6 $\pm 6,6$, y el grupo experimental es $29 \pm 3,8$. Se encontró diferencia significativa $\mathrm{P}<0,05$, es decir después del Programa de concientización jurídica, los estudiantes del grupo experimental sí desarrollaron avance significativo en la concientización del empoderamiento jurídico de los derechos humanos.

FIGURA 12. LAMEDIAEN DERECHOS HUMANOSENTRE ELGRUPO DE CONTROL ES 9,6 $\pm 6,6$, Y EL GRUPO EXPERIMENTAL ES $29 \pm 3,8$. SE ENCONTRÓ DIFERENCIA SIGNIFICATIVA DESPUÉS DEL PROGRAMA DE CONCIENTIZACIÓN JURÍDICA

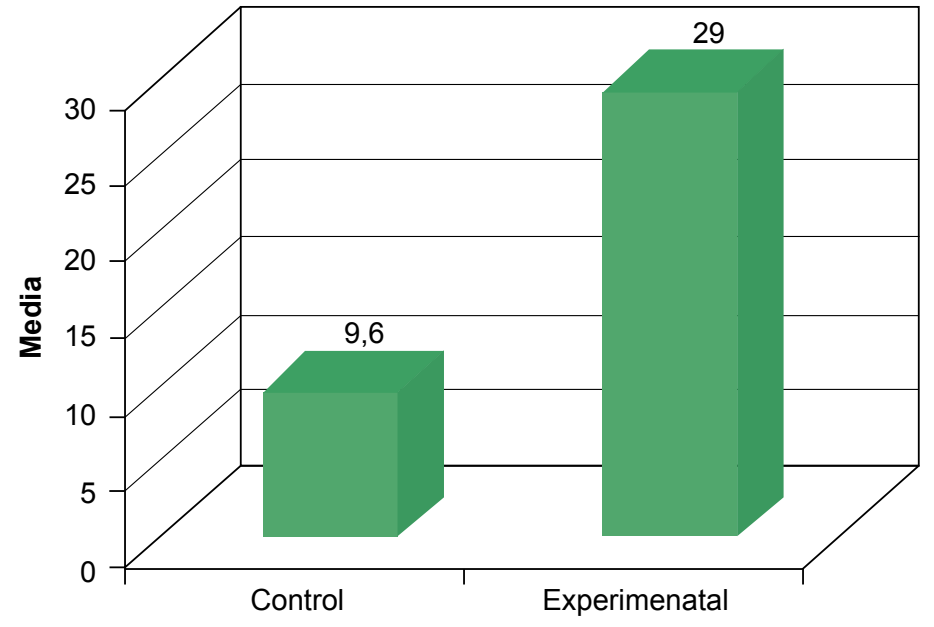




\section{DISCUSIÓN DE RESULTADOS}

La educación en DD.HH. es el camino que sirve para construir una democracia participativa, que nos lleva a pensar y analizar críticamente los hechos cotidianos, a proponer alternativas inteligentes ante el autoritarismo y a trabajar por la vigencia plena de los derechos humanos.

Es en ese contexto que se analizarán las tablas desarrolladas. De la tabla 1 se observa que la media del puntaje en derechos humanos de primera generación entre el grupo de control es al final 4,2 $\pm 4,1$, y el grupo experimental es al final $14 \pm 2,9$. Se encontró diferencia significativa. Asimismo de la tabla se observa que la media del puntaje en derechos humanos de primera generación al inicio en el grupo de control es $4,1 \pm 4,2$, y la media del puntaje en derechos humanos de primera generación al final en el grupo de control es $4,2 \pm 4,1$. No se encontró diferencia significativa; sin embargo, después del Programa de concientización jurídica en el empoderamiento de los derechos humanos en el grupo experimental sí desarrollaron avances significativos en la concientización jurídica en la dimensión derechos humanos de primera generación. También de la tabla 2 se observa que la media del puntaje en derechos humanos de segunda generación entre el grupo de control al final es $2 ., 4 \pm 2$, y el grupo experimental es $6,9 \pm 1,9$. Se encontró diferencia significativa. De la tabla se observa que la media del puntaje en derechos humanos de segunda generación al inicio en el grupo de control es 2,3 $\pm 2,1$, y la media del puntaje en derechos humanos de segunda generación, al final en el grupo de control es $2,4 \pm 2$. No se encontró diferencia significativa, es decir que después del Programa de concientización jurídica en el grupo experimental sí se desarrollaron avances significativos en la concientización jurídica en la dimensión derechos humanos de segunda generación. De la tabla 3 se observa que la media del puntaje en derechos humanos de tercera generación entre el grupo de control al final es $3,1 \pm 2,5$, y el grupo experimental al final es $8 \pm 1,8$. Se encontró diferencia significativa. Asimismo, de la tabla se observa que la media del puntaje en derechos humanos de tercera generación al inicio en el grupo control es $3,2 \pm 2,5$, y la media del puntaje en producción de textos al final en el grupo de control es $3,1 \pm 2,5$. No se encontró diferencia significativa, es decir que después del Programa de concientización jurídica en el grupo experimental sí se desarrollaron avances significativos en la concientización jurídica en la dimensión derechos humanos de tercera generación. De la tabla 4 se observa que la media del puntaje en empoderamiento de los derechos humanos entre en el grupo de control al final es 9,6 $\pm 6,7$, y el grupo experimental es $29 \pm 3,8$. Se encontró diferencia significativa, Asimismo, de la tabla se observa que la media del puntaje en empoderamiento de los derechos humanos al inicio en el grupo de control es $9,6 \pm 6,8$, y la media del puntaje en comunicación al final en el grupo de control es $9,6 \pm 6,7$, donde no hay diferencia significativa, es decir, después del Programa de concientización jurídica en el grupo experimental sí se desarrollaron avances significativos en la concientización jurídica en los derechos humanos. 


\section{CONCLUSIONES}

1. Se encontraron diferencias significativas, es decir que después del Programa de concientización jurídica, los estudiantes del grupo experimental sí desarrollaron avances significativos en el empoderamiento en la dimensión derechos humanos de primera generación.

2. Se encontraron diferencias significativas, es decir que después del Programa de concientización jurídica, los estudiantes del grupo experimental sí desarrollaron avances significativos en el empoderamiento en la dimensión derechos humanos de tercera generación.

3. Se encontraron diferencias significativas, es decir que después del Programa de concientización jurídica, los estudiantes del grupo experimental sí desarrollaron avances significativos en el empoderamiento en la dimensión derechos humanos de tercera generación.

4. Y por último se encontraron diferencias significativas, es decir que después del Programa de concientización jurídica, los estudiantes del grupo experimental sí desarrollaron avances significativos en el empoderamiento de los derechos humanos, en la IE Isaías Ardiles 7026 de Pachacámac.

\section{REFERENCIAS}

- Asamblea General de de las Naciones Unidas. Preámbulo de la Declaración de los Derechos Humanos. París: ONU, 1948.

- Comisión Nacional de los Derechos Humanos. CNDH. Acceso el 31 de marzo de 2016. www.cndh.org.mx/losdh/losdh.htm

- P. Corilloclla Terbullino. "El derecho fundamental a gozar de un ambiente equilibrado y adecuado como un derecho individual y social". Tesis para optar título de abogado. UNMSM, 2006.

- Naciones Unidas. Organización de Naciones de Derechos Humanos. Acceso el 26 de marzo de 2016. http://www.ohchr.org/SP/Issues/Pages/WhatareHumanRights.aspx

- Organización de los Derechos Humanos. La ONU y los derechos humanos. Acceso el 31 de marzo de 2016. http://www.un.org/es/rights/overview/ 
- Pariachi, C. Z. Repositorio PUCP. Equidad en el acceso al agua en la ciudad de Lima. Acceso el 31 de marzo de 2016. http://tesis.pucp.edu.pe/repositorio/bitstream/handle/123456789/1365/COTO_JOSE_ROMERO_ROSSMERY_EQUIDAD_MIRADA. pdf?sequence $=1$ \&isAllowed $=\mathrm{y}$

- Quintana, Tomás Ojea. Reflexiones sobre la indivisibilidad de los derechos humanos: el problema de los derechos económicos, sociales y culturales. Acceso el 26 de marzo de 2016. http:// www.carlosmanzano.net/articulos/Ojeaquintana.html

- Ruiz, O. V. Escuela de postgrado. Acceso el 31 de marzo de 2016. https://ruidera.uclm.es/ xmlui/bitstream/handle/10578/3491/TESIS\%20Valles\%20Ruiz.pdf?sequence=1

RECIBIDO: $1 / 08 / 2018$

APROBADO: 18/10/2018 


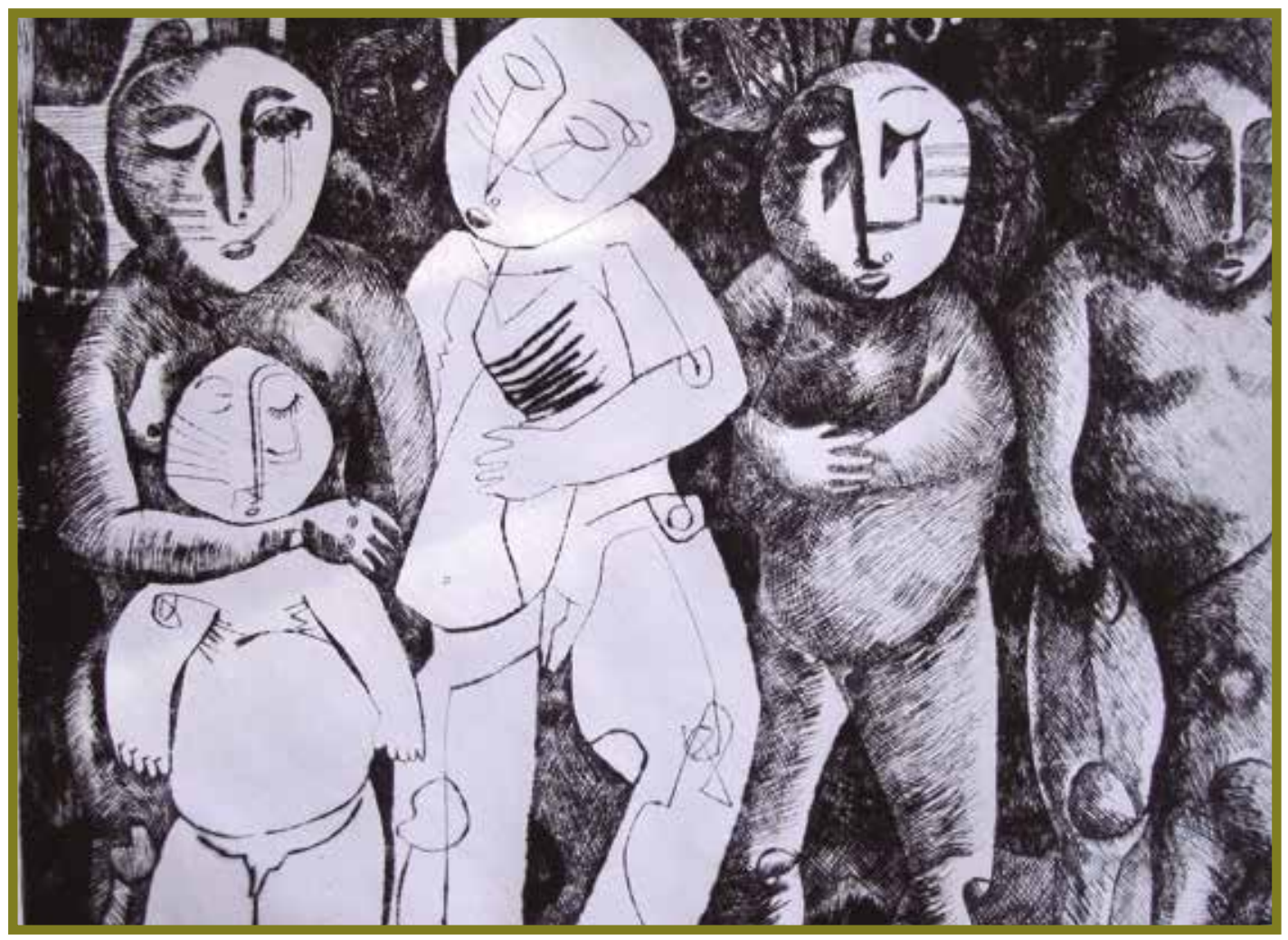

Familia. Grabado. Juan Carlos Nananake. 